Cite this: J. Mater. Chem. A, 2013, 1, 14973

Received 20th September 2013 Accepted 17th October 2013

DOI: $10.1039 / c 3 \operatorname{ta} 13778 c$

www.rsc.org/MaterialsA

\section{Low band gap dithienogermolodithiophene copolymers with tunable acceptors and side-chains for organic solar cells $\uparrow$}

\author{
Hongliang Zhong, ${ }^{a}$ Zhe Li, $^{\text {a }}$ Ester Buchaca-Domingo, ${ }^{\mathrm{b}}$ Stephan Rossbauer, ${ }^{\mathrm{c}}$ \\ Scott E. Watkins, ${ }^{d}$ Natalie Stingelin, ${ }^{b}$ Thomas D. Anthopoulos ${ }^{c}$ and Martin Heeney ${ }^{* a}$
}

We report the synthesis and characterisation of five new donor-acceptor type co-polymers based on a fused dithienogermolodithiophene unit for use in photovoltaic devices. The influence of three electron deficient co-monomers, as well as the length and variety of the solubilising side-chains, on the physical and optoelectronic properties of the polymers is reported. The number and variety of alkyl side-chains is found to have a significant impact on the polymer aggregation and film morphology, with larger and more bulky side-chains leading to improved solubility and molecular weight. The influence of these properties upon the performance of bulk heterojunction solar cells is shown.

\section{Introduction}

Conjugated polymers have attracted remarkable attention over the past decades due to their interesting optoelectronic properties, which have seen them utilised in applications such as organic field effect transistors (OFET) ${ }^{1}$ and photovoltaic cells $(\mathrm{OPV})^{2,3}$ In particular donor-acceptor copolymers consisting of electron rich donor monomers and electron deficient acceptor monomers have proven to be promising candidate materials for many of these potential applications. ${ }^{4}$ The donor-acceptor interaction can result in small band gap polymers, e.g. less than $1.8 \mathrm{eV}^{3}$ Thus the absorption of such polymers can be better matched to the solar spectrum, ${ }^{5}$ leading an enhancement of photovoltaic conversion efficiency at AM1.5. Furthermore, the energy levels of such donor-acceptor polymers can be tuned by the utilisation of different combinations of donor and acceptor monomers. The control of energy levels is particularly important for solar cell blends to ensure efficient charge transfer to the acceptor material, commonly a fullerene derivative such as PCBM in bulk heterojunction (BHJ) devices. ${ }^{6}$ In addition intramolecular charge transfer (ICT) ${ }^{7}$ from electron donor to acceptor may also be beneficial for charge separation and transport along the polymer backbone. There has been much work developing new donor and acceptor monomers and

${ }^{a}$ Dept. Chemistry and Centre for Plastic Electronics, Imperial College London, London, SW7 2AZ, UK. E-mail: m.heeney@imperial.ac.uk

${ }^{b}$ Dept. Materials and Centre for Plastic Electronics, Imperial College London, London, SW7 2AZ, UK

${ }^{C}$ Dept. Physics and Centre for Plastic Electronics, Imperial College London, London, $S W 72 A Z, U K$

${ }^{d}$ CSIRO, Molecular and Health Technologies, VIC 3169, Australia

$\dagger$ Electronic supplementary information (ESI) available: DSC plots and NMR spectra. See DOI: $10.1039 / \mathrm{c} 3 \mathrm{ta} 13778 \mathrm{c}$ polymeric combinations thereof, leading to continuing improvements in material performance in a variety of applications. ${ }^{8,9}$ However in order to maintain this progress it is important that new materials are developed, and in particular the relationship between different combinations of donor and acceptor monomers on polymeric properties is explored. ${ }^{\mathbf{1 0}}$

Amongst the various donor monomers utilised, thieno[3,2- $b]$ thiophene (TT) derivatives ${ }^{11-14}$ have been widely utilized to enhance device performance in the fields of OFET and OPV, where the incorporation of the rigid and rotationally invariant TT unit generally improves the planarity of the polymer backbone resulting in an improvement of charge carrier mobility. ${ }^{15,16}$ In addition the incorporation of TT often results in a decrease of the HOMO level of the resultant polymer leading an enhancement of open circuit voltage $\left(V_{\text {oc }}\right)$ in OPV devices. ${ }^{17-20}$ In particular, polymers containing TT units have featured strongly in the relatively small class of materials exhibiting power conversion efficiencies (PCE) over 7\%. ${ }^{\mathbf{1 4 , 2 1 - 2 3}}$ To date most of these reports have concentrated on the comparison between TT donors and their thiophene analogues, with fewer reports on the influence of different acceptors on polymer properties. Therefore, it is of interest to investigate the optoelectronic properties of copolymers of TT donors and various electron deficient acceptor comonomers in an effort to further understand the structure property relationships in this class of polymer.

$\mathrm{Yu}$ and his co-workers ${ }^{21}$ have reported a high efficiency 7.6\% polymer (PTDBD) based on dithieno[2,3- $\left.d: 2^{\prime}, 3^{\prime}-d^{\prime}\right]$ benzo[1,2$\left.b: 4,5-b^{\prime}\right]$ dithiophene, which is modified from benzo[1,2-b:4,5- $\left.b^{\prime}\right]$ dithiophene by extending the conjugation length with TT instead of thiophene. It is notable that the performance of this polymer depended significantly on the nature of the substituted side-chains utilised, even for the same backbone structure. To 
facilitate solution processability, the attachment of alkyl sidechains to the polymer backbone is required to lower the melting temperature and promote solubility. Besides improving the film forming properties, the side-chains are also able to influence the morphology and microstructure of the active layer in $\mathrm{BHJ}$ through affecting the intermolecular aggregation of polymers in the solid state. ${ }^{24}$ Thus, the choice of suitable side-chains is important for conjugated polymers to achieve high performance. ${ }^{25}$

Recently we reported a novel ladder-type fused dithienogermolodithiophene donor (DTTG), in which two linked TT units are bridged by a dialkylgermanium group. The copolymer (pDTTG-TPD) of DTTG with $N$-octylthienopyrrolodione (TPD) exhibited a promising solar cell performance, with a device PCE of $7.2 \%$ achieved without the use of any processing additives. ${ }^{23}$ This exciting result inspired us to further investigate the potential of DTTG as a donor monomer. We hereby report a series of DTTG polymers by copolymerization with the acceptors TPD, 2,1,3-benzothiadiazole (BT) and diketopyrrolopyrrole (DPP). In addition two different alkyl chains, 2-ethylhexyl and 2-octyldodecyl, are employed on the bridging germanium group to study the influence of side-chains on morphology and performance of devices.

\section{Experimental}

All starting materials and reagents were purchased from commercial sources and used without further purification unless otherwise stated. All solvents were anhydrous and syringes which were used to transfer reagents or solvents were purged with Argon prior to use. Microwave reactions were performed in a Biotage initiator V 2.3 in constant heating mode. NMR spectra were recorded on a Bruker AV-400 spectrometer using TMS as internal standard with deuterated tetrachloroethane as solvent at $130{ }^{\circ} \mathrm{C}$. Number-average (Mn) and weightaverage (Mw) were determined on an Agilent Technologies 1200 series GPC running in chlorobenzene at $80{ }^{\circ} \mathrm{C}$, using two $\mathrm{PL}$ mixed B columns in series, and calibrated against narrow polydispersity polystyrene standards. Tin monomers were purified on a custom built preparative recycling Shimadzu SEC system. The system comprises a DGU-20A3 degasser, an LC-20A pump, a CTO-20A column oven, an Agilent PLgel $10 \mu \mathrm{m}$ MIXEDD column and a SPD-20A UV detector. Elemental analysis was performed with a Thermo EA1108 or FlashEA1112 elemental analyser. UV-vis spectra were recorded with a UV-1601 Shimadzu UV-Vis spectrometer. Photoelectron Spectroscopy in Air (PESA) were determined with a Riken Keiki AC-2 PESA spectrometer with a power setting of $5 \mathrm{nW}$ and a power number of 0.5 using a sample prepared by spin-coating on a glass substrate. AFM images were obtained with a Picoscan PicoSPM LE scanning probe in tapping mode. X-ray diffraction scans were measured with a Panalytical X'Pert-pro MRD diffractometer equipped with a nickel-filtered $\mathrm{Cu} \mathrm{K} \alpha$ source and X'Celerator detector, using current $I=40 \mathrm{~mA}$ and accelerating voltage $V=40 \mathrm{kV}$. Samples were prepared on glass substrate by drop casting.

2,7-Bis(trimethylstannyl)-9,9-bis(2-ethylhexyl)-9H-thieno[3,2-b]thieno[ $\left[2^{\prime \prime}, 3^{\prime \prime}: 4^{\prime}, 5^{\prime}\right]$ thieno $\left[2^{\prime}, 3^{\prime}: 4,5\right]$ germolo$[2,3-d]$ thiophene $(\mathbf{4 a}),{ }^{23}$ (3,3'-dibromo-2,2'-bithieno[3,2- $b]$ thiene-5, $5^{\prime}$-diyl)bis(trimethylsilane) (1), ${ }^{23}$ dibromobis(2-octyldodecyl) germane ${ }^{26}$ and 1,3-dibromo-5octyl-4H-thieno[3,4-c]pyrrole-4,6(5H)-dione ${ }^{27}$ were synthesized following the same procedures reported previously.

\section{$\left[9,9-B i s(2-o c t y l d o d e c y l)-9 H\right.$-thieno[ $[3,2-b]$ thieno $\left[2^{\prime \prime}, 3^{\prime \prime}: 4^{\prime}, 5^{\prime}\right]$ - thieno[ $\left[2^{\prime}, 3^{\prime}: 4,5\right]$ germolo[2,3- $\left.d\right]$ thiene-2,7-diyl]- bis(trimethylsilane) (2b)}

In a dry $250 \mathrm{~mL}$ three-necked round bottom flask, (3,3'-dibromo2,2'-bithieno[3,2-b] thiene-5, $5^{\prime}$-diyl)bis(trimethylsilane) (1) (580 mg, $1.0 \mathrm{mmol})$ was dissolved in anhydrous diethyl ether $(100 \mathrm{~mL})$, then BuLi (1.6 M in hexane, $2.0 \mathrm{mmol}$ ) was added drop wise at $-90{ }^{\circ} \mathrm{C}$ under argon atmosphere. The reaction was stirred at $-90^{\circ} \mathrm{C}$ for 30 minutes, followed by the addition of a solution of dibromobis(2-octyldodecyl) germane $(875 \mathrm{mg}, 1.1 \mathrm{mmol})$ in diethyl ether $(5 \mathrm{~mL})$. The mixture was allowed to warm to room temperature slowly. After stirring for another 30 minutes, the resulting solution was poured into water $(200 \mathrm{~mL})$ and extracted with diethyl ether. The organic phase was washed by water and brine, dried over anhydrous $\mathrm{MgSO}_{4}$ and evaporated. The residue was purified by flash chromatography on silica gel (hexane) to afford $2 \mathbf{b}(560 \mathrm{mg}, 0.53 \mathrm{mmol}, 53 \%$ ) as yellow oil. ${ }^{1} \mathrm{H}$ NMR (400 MHz, $\left.\mathrm{CDCl}_{3}\right) \delta 7.34(\mathrm{~s}, 2 \mathrm{H}), 1.56(\mathrm{~m}, 2 \mathrm{H}), 1.40(\mathrm{~d}$, $J=6.5,4 \mathrm{H}), 1.15(\mathrm{~m}, 64 \mathrm{H}), 0.88(\mathrm{~m}, 12 \mathrm{H}), 0.36(\mathrm{~m}, 18 \mathrm{H}) .{ }^{13} \mathrm{C}$ NMR (100 MHz, $\left.\mathrm{CDCl}_{3}\right) \delta 149.27,147.81,142.11,134.24$, 125.78, 36.53, 35.58, 31.93, 29.78, 29.40, 26.87, 22.71, 21.22, 14.13, -0.16. MS (MALDI): $m / z 1056\left(\mathbf{M}^{+}\right)$.

\section{2,7-Dibromo-9,9-bis(2-octyldodecyl)-9H-thieno[3,2-b]thieno-} $\left[2^{\prime \prime}, 3^{\prime \prime}: 4^{\prime}, 5^{\prime}\right]$ thieno $\left[2^{\prime}, 3^{\prime}: 4,5\right]$ germolo $[2,3-d]$ thiophene $(3 b)$

To a solution of [9,9-bis(2-octyldodecyl)-9H-thieno[3,2- $b]$ thieno $\left[2^{\prime \prime}, 3^{\prime \prime}: 4^{\prime}, 5^{\prime}\right]$ thieno[2' $\left.2^{\prime} 3^{\prime}: 4,5\right]$ germolo[2,3- $\left.d\right]$ thiene-2,7-diyl]bis(trimethylsilane) (2b) $(530 \mathrm{mg}, 0.50 \mathrm{mmol})$ in THF $(50 \mathrm{~mL})$, $N$-bromosuccinimide (187 $\mathrm{mg}, 1.05 \mathrm{mmol}$ ) was added in three portions and then the mixture was stirred overnight in the absence of light. The mixture was quenched by aqueous $\mathrm{Na}_{2} \mathrm{SO}_{3}$ solution and extracted with diethyl ether. The organic phase was washed by water and brine, dried over anhydrous $\mathrm{MgSO}_{4}$, evaporated and chromatographed on silica gel (hexane) to give $3 \mathbf{b}(310 \mathrm{mg}, 0.29 \mathrm{mmol}, 58 \%)$ as yellow oil. ${ }^{1} \mathrm{H}$ NMR (400 MHz, $\left.\mathrm{CDCl}_{3}\right) \delta 7.27(\mathrm{~s}, 2 \mathrm{H}), 1.51(\mathrm{~s}$, $2 \mathrm{H}), 1.38(\mathrm{~d}, J=6.4,4 \mathrm{H}), 1.17(\mathrm{~m}, 64 \mathrm{H}), 0.89(\mathrm{~m}, 12 \mathrm{H}) .{ }^{13} \mathrm{C}$ NMR $\left(100 \mathrm{MHz}, \mathrm{CDCl}_{3}\right) \delta 147.33,143.09,138.70,134.49$, 122.46, 111.57, 36.50, 31.93, 29.64, 26.78, 22.71, 14.13. MS (MALDI): $m / z 1068\left(\mathbf{M}^{+}\right)$.

\section{2,7-Bis(trimethylstannyl)-9,9-bis(2-octyldodecyl)-9H-thieno- $[3,2-b]$ thieno $\left[2^{\prime \prime}, 3^{\prime \prime}: 4^{\prime}, 5^{\prime}\right]$ thieno $\left[2^{\prime}, 3^{\prime}: 4,5\right]$ germolo $[2,3-d]$ - thiophene (4b)}

To a solution of 2,7-dibromo-9,9-bis(2-octyldodecyl)-9Hthieno[3,2- $b]$ thieno $\left[2^{\prime \prime}, 3^{\prime \prime}: 4^{\prime}, 5^{\prime}\right]$ thieno $\left[2^{\prime}, 3^{\prime}: 4,5\right]$ germolo[2,3- $\left.d\right]$ thiophene (3b) (510 $\mathrm{mg}, 0.48 \mathrm{mmol}$ ) in anhydrous diethyl ether $(50 \mathrm{~mL}), t$-BuLi (1.6 $\mathrm{M}$ in hexane, $1 \mathrm{mmol}$ ) was added drop wise under argon atmosphere at $-90{ }^{\circ} \mathrm{C}$, followed by stirring for 30 minutes. Trimethyltin chloride solution (1 M in THF, $1.1 \mathrm{mmol}$ ) was added, and then the reactant mixture 
was allowed to warm to room temperature slowly and stirred overnight. The reaction quenched by water, extracted with diethyl ethyl and the combined organics were washed by water and brine, dried over anhydrous $\mathrm{MgSO}_{4}$ and concentrated. The crude product was purified by recycling GPC (hexane) to afford compound 4b (320 mg, $0.26 \mathrm{mmol}, 54 \%)$ as a yellow oil. ${ }^{1} \mathrm{H} \mathrm{NMR}\left(400 \mathrm{MHz}, \mathrm{CDCl}_{3}\right.$ ) $\delta 7.28(\mathrm{~s}, 2 \mathrm{H}), 1.56(\mathrm{~m}, 2 \mathrm{H}), 1.39(\mathrm{~d}, J=6.5,4 \mathrm{H}), 1.14(\mathrm{~m}$, $64 \mathrm{H}), 0.87(\mathrm{~m}, 12 \mathrm{H}), 0.40(\mathrm{~m}, 18 \mathrm{H}) .{ }^{13} \mathrm{C}$ NMR $(100 \mathrm{MHz}$, $\left.\mathrm{CDCl}_{3}\right) \quad \delta$ 149.05, 148.49, 142.29, 139.50, 133.80, $126.79,36.52,35.58,31.95,29.70,29.42,26.84,22.72$, $21.21,14.14,-8.26$.

Poly $[2,7(9,9-b i s(2-e t h y l h e x y l)-9 H$-thieno[3,2-b]thieno$\left[2^{\prime \prime}, 3^{\prime \prime}: 4^{\prime}, 5^{\prime}\right]$ thieno $\left[2^{\prime}, 3^{\prime}: 4,5\right]$ germolo[2,3-d] thiophene)-alt(2,1,3-benzothiadiazole)-4,7-diyl] (pDTTG-BT)

4,7-Dibromo-2,1,3-benzothiadiazole (25 mg, $0.084 \mathrm{mmol}$ ), 2,7-bis(trimethylstannyl)-9,9-bis(2-ethylhexyl)-9H-thieno[3,2$b]$ thieno[ $\left[2^{\prime \prime}, 3^{\prime \prime}: 4^{\prime}, 5^{\prime}\right]$ thieno $\left[2^{\prime}, 3^{\prime}: 4,5\right]$ germolo[2,3- $\left.d\right]$ thiophene (4a) $(76 \mathrm{mg}, 0.084 \mathrm{mmol}), \mathrm{Pd}_{2}(\mathrm{dba})_{3}(1.5 \mathrm{mg}, 0.0017 \mathrm{mmol})$ and $\mathrm{P}(o \text {-tol })_{3}(2.0 \mathrm{mg}, 0.0067 \mathrm{mmol})$ were added to a $2.0 \mathrm{~mL}$ high pressure microwave reactor tube. After flushing with argon, $1.0 \mathrm{~mL}$ degassed chlorobenzene was added. Then the tube was submitted to the following temperature scheme in the microwave reactor: 2 minutes at $100{ }^{\circ} \mathrm{C}, 2$ minutes at $120{ }^{\circ} \mathrm{C}, 2$ minutes at $140{ }^{\circ} \mathrm{C}, 2$ minutes at $160{ }^{\circ} \mathrm{C}, 20$ minutes at $180{ }^{\circ} \mathrm{C}$ and 20 minutes at $200{ }^{\circ} \mathrm{C}$. Timing was commenced once the reaction reached the appropriate temperature. After the mixture was cooled to room temperature, 2-(tributylstannyl)thiophene $(3.0 \mathrm{mg}, 0.008 \mathrm{mmol})$ and $\operatorname{Pd}_{2}(\mathrm{dba})_{3}$ ( $7.7 \mathrm{mg}, 0.008 \mathrm{mmol}$ ) in $0.1 \mathrm{~mL}$ chlorobenzene were added by syringe. The tube was subjected to the microwave reactor with the following condition: 1 minute at $100{ }^{\circ} \mathrm{C}, 1$ minute at $120{ }^{\circ} \mathrm{C}, 1$ minute at $140{ }^{\circ} \mathrm{C}, 1$ minute at $160^{\circ} \mathrm{C}$ and 10 minutes at $180^{\circ} \mathrm{C}$. The crude polymer was precipitated into methanol and then purified by Soxhlet extractions sequentially with methanol, acetone, hexane, THF and chlorobenzene. The chlorobenzene solution was concentrated and precipitated into methanol, to afford pDTTG-BT as a dark solid (42 mg, $0.059 \mathrm{mmol}, 70 \%)$. GPC: $M_{\mathrm{n}}=10000$, PDI 3.5. ${ }^{1} \mathrm{H} \mathrm{NMR}$ (500 MHz, d $\mathrm{d}_{2}-1,1,2,2$-tetrachloroethane, $130{ }^{\circ} \mathrm{C}$ ) $\delta 8.56$ (br, 2H), 7.93 (br, 2H), 1.48 (m, 22H), 0.92 (m, 12H). Anal. calcd for $\left(\mathrm{C}_{34} \mathrm{H}_{38} \mathrm{GeN}_{2} \mathrm{~S}_{5}\right)_{\mathrm{n}}$ : C, 57.71; H, 5.41; N, 3.96; S, 22.66. Found: C, 56.36; H, 5.16; N, 3.99; S, 21.98.

Poly $[2,7(9,9-b i s(2-e t h y l h e x y l)-9 H$-thieno[3,2-b]thieno$\left[2^{\prime \prime}, 3^{\prime \prime}: 4^{\prime}, 5^{\prime}\right]$ thieno[ $\left[2^{\prime}, 3^{\prime}: 4,5\right]$ germolo[2,3-d] thiophene)-alt-3,6bis(thiophen-5-yl)-2,5-di-hexadecyl-2,5-dihydropyrrolo[3,4-c]pyrrole-1,4-dione] (pDTTG-DPP)

pDTTG-DPP was synthesized and purified following the same procedure for pDTTG-BT. pDTTG-DPP was obtained as a dark solid (65 mg, 82\%). GPC: $M_{\mathrm{n}}=32000$, PDI 2.0. ${ }^{1} \mathrm{H}$ NMR (500 $\mathrm{MHz}, \mathrm{d}_{2}-1,1,2,2$-tetrachloroethane, $130{ }^{\circ} \mathrm{C}$ ) $\delta 8.90$ (br, 2H), 7.40 (m, 4H), $3.84(\mathrm{~m}, 4 \mathrm{H}), 1.68(\mathrm{~m}, 78 \mathrm{H}), 0.91(\mathrm{~m}, 18 \mathrm{H})$. Anal. calcd for $\left(\mathrm{C}_{74} \mathrm{H}_{106} \mathrm{GeN}_{2} \mathrm{O}_{2} \mathrm{~S}_{6}\right)_{\mathrm{n}}$ : C, 67.30; $\mathrm{H}, 8.09 ; \mathrm{N}, 2.12 ; \mathrm{S}, 14.57$. Found: C, 64.81; H, 7.79; N, 2.17; S, 13.38.
Poly $[2,7(9,9-b i s(2-o c t y l d o d e c y l)-9 H$-thieno[3,2-b]thieno$\left[2^{\prime \prime}, 3^{\prime \prime}: 4^{\prime}, 5^{\prime}\right]$ thieno[ $\left[2^{\prime}, 3^{\prime}: 4,5\right]$ germolo $[2,3-d]$ thiophene)-alt(2,1,3-benzothiadiazole)-4,7-diyl] (pDTTGL-BT)

pDTTGL-BT was gained as a dark solid (156 mg, 75\%) by the same polymerization and purification procedure for pDTTG-BT. GPC: $M_{\mathrm{n}}=26000$, PDI 3.4. ${ }^{1} \mathrm{H}$ NMR $\left(500 \mathrm{MHz}, \mathrm{d}_{2}-1,1,2,2\right.$-tetrachloroethane, $\left.130{ }^{\circ} \mathrm{C}\right) \delta 8.59(\mathrm{~s}, 2 \mathrm{H}), 7.92(\mathrm{~s}, 2 \mathrm{H}), 1.46(\mathrm{~m}$, $70 \mathrm{H}), 0.91(\mathrm{~m}, 12 \mathrm{H})$. Anal. calcd for $\left(\mathrm{C}_{58} \mathrm{H}_{86} \mathrm{GeN}_{2} \mathrm{~S}_{5}\right)_{\mathrm{n}}: \mathrm{C}, 66.71$; H, 8.30; N, 2.68; S, 15.35. Found: C, 64.48; H, 8.77; N, 2.82; S, 14.41 .

Poly [2,7(9,9-bis(2-octyldodecyl)-9H-thieno[3,2-b]thieno$\left[2^{\prime \prime}, 3^{\prime \prime}: 4^{\prime}, 5^{\prime}\right]$ thieno[ $\left[2^{\prime}, 3^{\prime}: 4,5\right]$ germolo[2,3-d] thiophene)-alt-3,6bis(thiophen-5-yl)-2,5-di-octyldodecyl-2,5-dihydropyrrolo[3,4c]pyrrole-1,4-dione] (pDTTGL-DPP)

pDTTGL-DPP was gained as a dark solid (116 $\mathrm{mg}, 85 \%)$ by the same polymerization and purification procedure for PDTTG-BT.

GPC: $M_{\mathrm{n}}=75000$, PDI 2.0. ${ }^{1} \mathrm{H}$ NMR $\left(500 \mathrm{MHz}, \mathrm{d}_{2}-\right.$ 1,1,2,2-tetrachloroethane, $\left.130{ }^{\circ} \mathrm{C}\right) \delta 8.88(\mathrm{br}, 2 \mathrm{H}), 7.57(\mathrm{br}$, $2 \mathrm{H}), 7.40(\mathrm{br}, 2 \mathrm{H}), 4.12(\mathrm{~m}, 4 \mathrm{H}), 2.07(\mathrm{~m}, 2 \mathrm{H}), 1.43(\mathrm{~m}, 134 \mathrm{H})$, $0.94(\mathrm{~m}, 24 \mathrm{H})$. Anal. calcd for $\left(\mathrm{C}_{106} \mathrm{H}_{170} \mathrm{GeN}_{2} \mathrm{O}_{2} \mathrm{~S}_{6}\right)_{\mathrm{n}}$ : C, 71.95; H, 9.68; N, 1.58; S, 10.87. Found: C, 71.30; H, 10.50; N, 1.81; S, 10.92 .

Poly $[2,7(9,9-b i s(2-o c t y l d o d e c y l)-9 H$-thieno[3,2-b]thieno$\left[2^{\prime \prime}, 3^{\prime \prime}: 4^{\prime}, 5^{\prime}\right]$ thieno $\left[2^{\prime}, 3^{\prime}: 4,5\right]$ germolo $[2,3-d]$ thiophene)-alt1,3(5-octyl-4H-thieno[3,4-c]pyrrole-4,6(5H)-dione) (pDTTGLTPD)

pDTTGL-TPD was gained as a dark solid (122 $\mathrm{mg}, 81 \%$ ) by the same polymerization and purification procedure for PDTTG-BT.

GPC: $M_{\mathrm{n}}=36000$, PDI 1.8. ${ }^{1} \mathrm{H}$ NMR $\left(500 \mathrm{MHz}, \mathrm{d}_{2}-1,1,2,2-\right.$ tetrachloroethane, $\left.130{ }^{\circ} \mathrm{C}\right) \delta 8.52(\mathrm{br}, 2 \mathrm{H}), 3.79(\mathrm{~m}, 2 \mathrm{H}), 1.47(\mathrm{~m}$, $82 \mathrm{H}), 0.95(\mathrm{~m}, 15 \mathrm{H})$. Anal. calcd for $\left(\mathrm{C}_{66} \mathrm{H}_{101} \mathrm{GeNO}_{2} \mathrm{~S}_{5}\right)_{\mathrm{n}}: \mathrm{C}$, 67.55; H, 8.68; Ge, 6.19; N, 1.19; O, 2.73; S, 13.66. Found: C, $66.37 ; \mathrm{H}, 9.45 ; \mathrm{N}, 1.37$;, 13.33 .

\section{Organic photovoltaic device fabrication}

A conventional device configuration was employed: ITO/ PEDOT:PSS/Polymer: $\mathrm{PC}_{71} \mathrm{BM} / \mathrm{Ca} / \mathrm{Al}$. The precoated ITO glass substrates were cleaned by sonicating in water, acetone and isopropanol successively, followed by drying and oxygen plasma treatment. A $35 \mathrm{~nm}$ layer of PEDOT:PSS was spincoated onto the plasma-treated ITO substrate and baked at $150{ }^{\circ} \mathrm{C}$ for 20 minutes. A $100 \mathrm{~nm}$ active layer consisting of a $1: 2$ in weight ratio blend of polymer and $\mathrm{PC}_{71} \mathrm{BM}$ dissolved in 1,2-dichlorobenzene (DCB) was spin-coated on the PEDOT:PSS layer and then $\mathrm{Ca}(25 \mathrm{~nm}) / \mathrm{Al}(100 \mathrm{~nm})$ cathode was finally deposited by thermal evaporation under high vacuum $\left(10^{-6} \mathrm{mbar}\right)$ through a shadow mask. The pixel size, defined by the spatial overlap of the ITO anode and $\mathrm{Ca} / \mathrm{Al}$ cathode, was $0.045 \mathrm{~cm}^{2}$. Current density-voltage $(J-V)$ characteristics were measured using a Xenon lamp at AM1.5 solar illumination (Oriel Instruments) calibrated to a silicon reference cell with a Keithley 2400 source meter, correcting for spectral mismatch. 


\section{Results and discussion}

\section{Design, synthesis and characterization}

Regarding the choice of suitable electron deficient comonomers, the BT unit was chosen due to its strong electronaccepting ability, which can lead to a lower band gap compared to the previously reported TPD polymer. In addition the rigid and planar structure of BT is helpful to achieve a strong intermolecular stacking in the solid state. ${ }^{28,29}$ DPP based polymers are promising materials for organic solar cells, ${ }^{30}$ in particular for their excellent current density in BHJ devices, ${ }^{31}$ so pDTTGDPP was synthesized by copolymerization of DPP and the DTTG group. Regarding the choice of alkyl side-chains for the DTTG moiety, 2-ethylhexyl as previously investigated for pDTTG-TPD, was initially chosen. However in the case of the BT co-polymer we were aware that the lack of a solubilising side-chain on the BT monomer, unlike TPD or DPP, may lead to low polymer solubility in the case of the 2-ethylhexyl (EH) side-chain. Therefore longer and branched 2-octyldodecyl (OD) was utilized as an alternative side-chain for DTTG group to ensure good solubility (termed DTTGL throughout). In order to facilitate comparison to our previously reported polymer, the long alkyl chain DTTG was also co-polymerised with TPD. Finally in the case of DPP we also investigated monomers with a straight chain (hexadecyl) on the DPP core, in combination with $\mathrm{EH}$ DTTG, as well as a longer branched 2-octyldecyl on the DPP unit, in combination with DTTGL to ensure good solubility of the resultant polymer.

The DTTG monomers were synthesized in high yield using the methodology we developed previously, ${ }^{23}$ where cyclization reactions were employed with $\left(3,3^{\prime}\right.$-dibromo-2, $2^{\prime}$-bithieno[3,2- $\left.b\right]$ thiene-5, $5^{\prime}$-diyl)bis(trimethylsilane) (1) and the relevant dialkyldibromogermane derivatives. ${ }^{32}$ Following bromination with NBS, the required distannyl derivatives were obtained by cryogenic lithiation and reaction with trimethyltin chloride. The resulting stannyl monomers were purified by preparative GPC, due to the low stability of the stannyl group on silica. As shown in Scheme 1, the polymers were synthesized by Stille
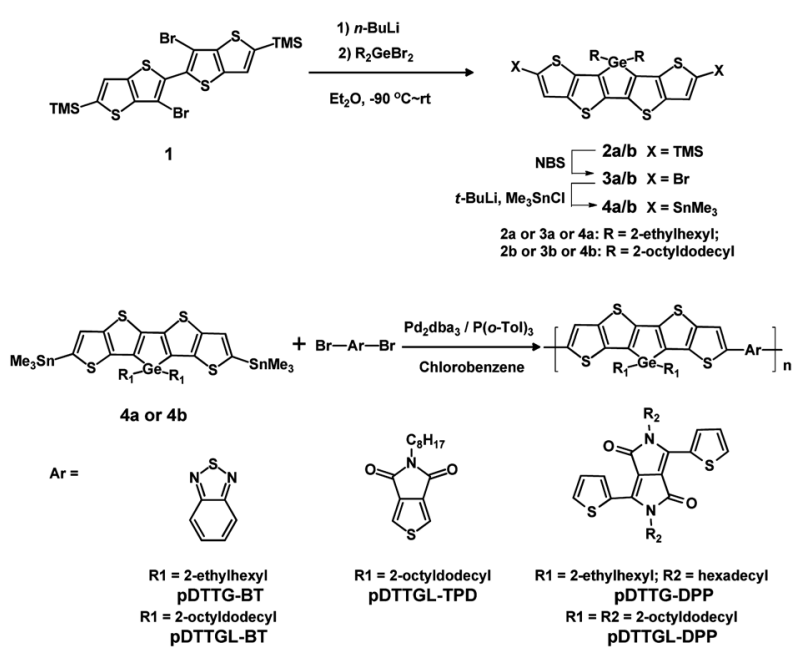

Scheme 1 Synthetic route to pDTTG-BT, pDTTG-DPP, PDTTGL-BT, pDTTGLTPD and pDTTGL-DPP. polymerization with the distannyl derivative of DTTG and the relevant dibromide comonomer under microwave-assisted coupling conditions. ${ }^{33}$ The crude polymers were end-capped in situ to limit the possible detrimental effect of the residual bromide. $^{34}$

After purification by precipitation and Soxhlet extraction to remove the catalyst residues and low molecular weight oligomers, the polymers were obtained as dark solids. As expected, the polymers with 2-ethylhexyl, in particular pDTTG-BT, show relatively poor solubility in common organic solvents, e.g. chloroform and chlorobenzene, and high solution temperatures were required to fully dissolve them. In contrast the situation was significantly improved for the polymers with longer alkyl chains. The solubility of pDTTGL-DPP and pDTTGL-TPD was good enough to prepare solutions even in hexane, whilst pDTTGL-BT could dissolve in hot common organic solvents like chlorobenzene.

The molecular weight and polydispersity data are shown in Table 1. We note that the molecular weights of the polymers with longer chains are significantly higher compared with their short-chain analogues. This can be explained by the fact that poor solubility of the growing chain can make polymers precipitate earlier in the reaction preventing further chain growth. In particular the polymers containing DPP cores, which contain two alkyl chains, exhibit the highest molecular weight, whereas the derivatives of BT, which have no solubilising group, show the lowest molecular weight and broadest polydispersity. These results indicate that the number and nature of the polymer side-chains have a significant influence on the molecular weight of the polymers formed.

The chemical structures of monomers and polymers were confirmed by ${ }^{1} \mathrm{H}$ NMR and elemental analysis. Due to strong intermolecular aggregation, high resolution NMR spectra could not be obtained in $\mathrm{CDCl}_{3}$ at room temperature. Through employment of a high boiling point deuterated solvent, $\mathrm{D}_{2}-1,1,2,2$-tetrachloroethane, high temperature NMR at $130{ }^{\circ} \mathrm{C}$ were obtained to improve the resolution (see ESI $\dagger$ ). Elemental analysis data exhibited good agreement with the theoretical calculations. The thermal properties of polymers were measured by differential scanning calorimetry (DSC). As shown in Fig. $\mathrm{S} 1, \dagger$ pDTTGL-DPP displays a single endothermic melting peak at $280{ }^{\circ} \mathrm{C}$ in the heating cycle and a single exothermic crystallization peak at $257^{\circ} \mathrm{C}$ in the cooling cycle. No obvious thermal transitions were observed between 0 and $300{ }^{\circ} \mathrm{C}$ for any of the other polymers.

\section{Optoelectronic properties}

To calculate the optimized molecular geometry and electronic distribution of the frontier orbitals of the polymers, density functional theory (DFT) calculations were carried out using Gaussian $09^{35}$ at the B3LYP ${ }^{36}$ level with the 6-31G(d) basis set. Excitation energies of the low-lying excited states were calculated with time-dependent DFT (TDDFT) at the same level and basis set level. In each case structures were allowed to relax to an equilibrium geometry from either an all-anticonformation or an all-trans geometry (with respect to the 
Table 1 Summary of molecular weights and optical properties of pDTTG-BT, pDTTG-DPP, pDTTGL-BT, pDTTGL-TPD and pDTTGL-DPP

\begin{tabular}{llllllll}
\hline Polymers & $M_{\mathrm{n}}{ }^{b}(\mathrm{kDa})$ & $\mathrm{PDI}$ & $\lambda_{\text {absmax }}(\mathrm{sol})^{c}(\mathrm{~nm})$ & $\lambda_{\mathrm{absmax}}(\mathrm{film})(\mathrm{nm})$ & $E_{\mathrm{g}}(\mathrm{eV})$ & $\mathrm{HOMO}^{d}(\mathrm{eV})$ & $\mathrm{LUMO}^{d}(\mathrm{eV})$ \\
\hline pDTTG-TPD $^{a}$ & 12 & 1.4 & 595,643 & 608,663 & 1.75 & -5.33 \\
pDTTG-BT & 10 & 3.5 & 669,712 & 684,717 & 1.57 & -5.14 \\
pDTTG-DPP & 32 & 2.0 & 478,692 & 472,706 & 1.38 & -5.20 \\
pDTTGL-TPD & 36 & 1.8 & 604 & 598,653 & 1.76 & -5.52 & -3.57 \\
pDTTGL-BT & 26 & 3.4 & 661,725 & 670,723 & 1.58 & -5.32 \\
pDTTGL-DPP & 75 & 2.0 & 778 & 708,779 & 1.33 & -5.65
\end{tabular}

${ }^{a}$ Data from ref. 23. ${ }^{b}$ Determined by GPC and reported as their polystyrene equivalents. ${ }^{c}$ Measured in dilute chlorobenzene solution. ${ }^{d}$ The HOMO energy was measured as a thin film by PESA (error $\pm 0.05 \mathrm{eV}$ ) and the LUMO energy was estimated by adding the optical band gap to the HOMO.

coupling between DTTG and the adjacent monomer), and the lowest overall energy conformers are shown. Trimers of polymers with methyl groups instead of longer side-chains were employed as models in order to simplify the calculations. Initially we thought the existence of hydrogen bonds between a $\beta$ hydrogen of the DTTG moiety and an adjacent thiadiazole or pyrrolidione groups in pDTTG-BT or pDTTGTPD might be a beneficial interaction to promote certain backbone conformations. However the calculation results suggest the alternative conformation is lower in energy, such that the polymer backbones appear as arc rather than linear structures. ${ }^{37,38}$ As shown in Fig. 1, the minimum-energy conformations of all three trimers reveal that all of the dihedral angles between donors and acceptors are less than $1^{\circ}$, indicating the polymers have planar conformations due to the rigid structure of DTTG. The planar backbones enhance the delocalization of both HOMO and LUMO along the backbone, which can be beneficial for charge transport. DFT calculations predict the HOMO/LUMO of pDTTG-BT, pDTTGTPD and pDTTG-DPP are $-4.58 /-3.14,-4.88 /-3.06$ and $-4.57 /-3.16 \mathrm{eV}$, respectively.

The optical properties of the five polymers in chlorobenzene and as spin-coated films were characterized by UV-vis absorption spectroscopy. The results are shown in Fig. 2 and Table 1 where the properties of PDTTG-TPD are also listed for comparison. The solution spectrum of pDTTG-BT shows a maximum absorption at
$669 \mathrm{~nm}$ with a $74 \mathrm{~nm}$ red-shift compared with pDTTG-TPD, which is rationalized by the stronger donor-acceptor interaction of the former. A shoulder peak appears at longer wavelengths for pDTTG-BT as well as pDTTG-TPD, suggesting that strong intermolecular aggregation is present even in dilute solution. Upon film formation for both polymers, the whole absorption red shifts slightly and the former shoulder peaks increase in intensity to become the maximum absorption, due to the enhancement of polymer stacking in the solid state. From the onset of absorption for the thin films, the optical band gap of pDTTG-BT was calculated as $1.57 \mathrm{eV}$, narrower than that of PDTTG-TPD $(1.75 \mathrm{eV})$, which should enhance the photocurrent in $\mathrm{BHJ}$ devices. This data suggests the inclusion of a stronger acceptor like BT enhances the strength of the ICT interaction, resulting in a reduced band gap. pDTTGL-BT and PDTTGL-TPD exhibit similar absorption spectra with their short chain analogues respectively, showing that alteration of the bridging alkyl chain did not detrimentally influence the band gap of polymers. However, a slight blue-shift and decrease in the relative intensity of the long wavelength shoulder peaks compared to the main peak in both pDTTGL-BT and PDTTGL-TPD suggests that polymer aggregation was inhibited by the longer alkyl chains, which may be detrimental for the performance of the polymers in solar cells.

Just as for other DPP derivatives, pDTTG-DPP shows a broad absorption from the visible to near-infrared range. Both the solution and film of PDTTG-DPP display two peaks at around

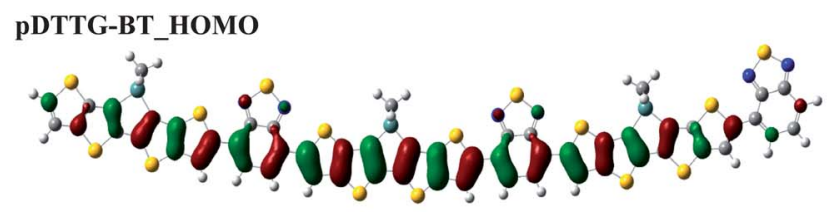

pDTTG-TPD_HOMO

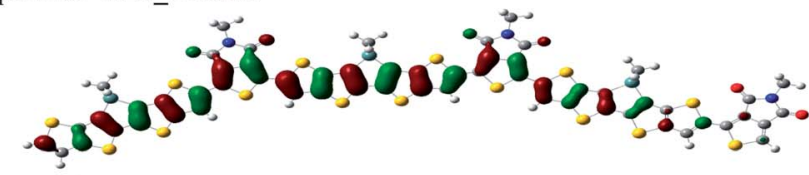

pDTTG-DPP_HOMO

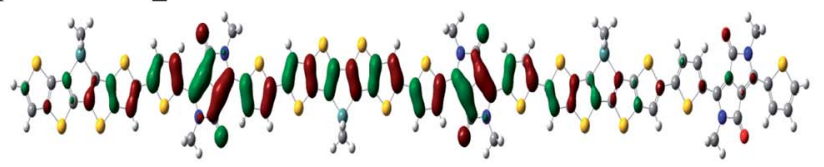

PDTTG-BT_LUMO

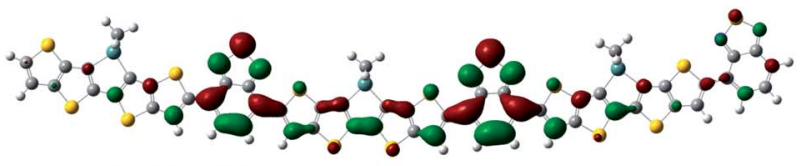

pDTTG-TPD_LUMO

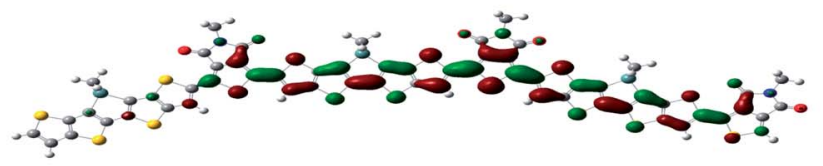

pDTTG-DPP_LUMO

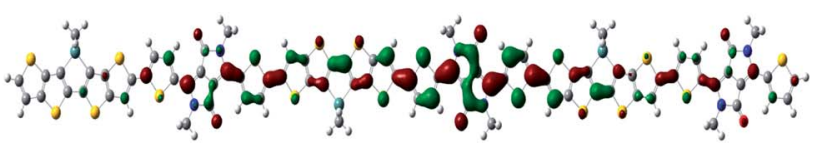

Fig. $1 \mathrm{HOMO}$ and LUMO distributions for the minimum-energy conformation calculated by Gaussian at the B3LYP/6-31G(d) level. 

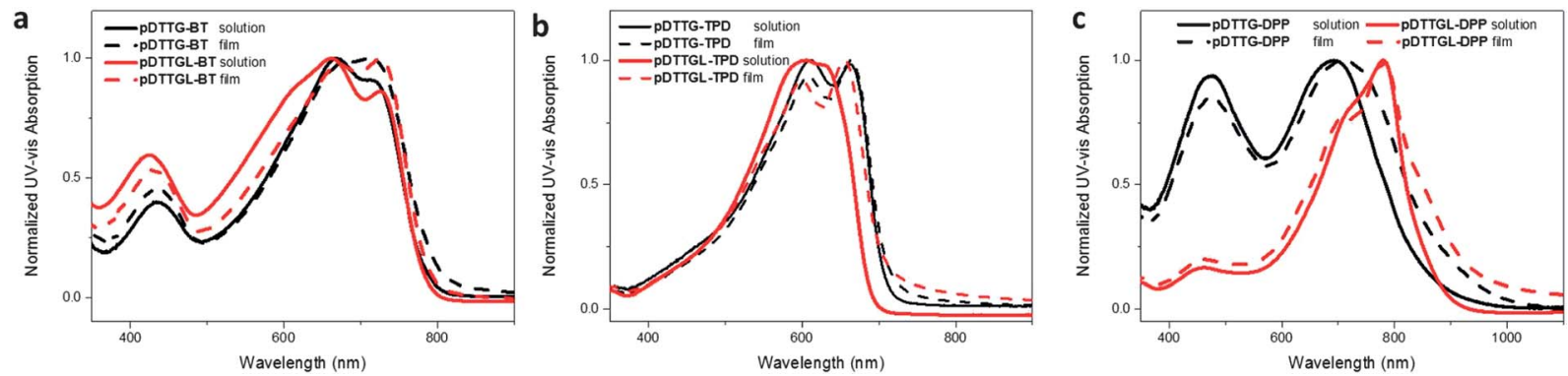

Fig. 2 UV-vis spectra of (a) pDTTG-BT, pDTTGL-BT, (b) pDTTG-TPD, pDTTGL-TPD and (c) pDTTG-DPP, pDTTGL-DPP in dilute chlorobenzene solutions and as thin film.

475 and $700 \mathrm{~nm}$, in which the short wavelength absorption is attributed to a localized $\pi-\pi *$ transition of DTTG with adjoining thiophene units and the longer wavelength one to the strong ICT between the DTTG donor and DPP unit. ${ }^{39}$ Comparing the spectra of the film with that of solution, the film shows a slight red-shift due to the increase of molecular order in the solid state.

It is notable that pDTTGL-DPP shows a $70 \mathrm{~nm}$ red-shift in $\lambda_{\max }$ and a significant decline in the short wavelength peak intensity relative to $\lambda_{\max }$, in comparison to the short alkyl chain derivative (Fig. 2c), whereas a blue-shift was observed in both pDTTGL-BT and pDTTGL-TPD as mentioned previously. We believe this may be due to differences in torsion angles between the unsubstituted thiophene linker and its adjacent groups, i.e. the diketopyrrolopyrrole core and the DTTG moiety in both polymers. We speculate that this thiophene is better able to be co-planar with DTTG group since the alkyl chains of DTTG are further away in space compared to the DPP, leading to a steric twist between the unsubstituted thiophene and the DPP core to break the conjugation. However when the 2-ethylhexyl on the DTTG is replaced with the larger 2-octyldodecyl we suggest that similar steric hindrance now occurs between the unsubstituted thiophene and both the DPP core and the DTTG group, forcing the two torsion angles of thiophene to be nearly equal so that the whole polymer backbone of PDTTGL-DPP tends to be more coplanar resulting in the establishment of a larger delocalized conjugation to change the absorption. The optical band gaps of these two DPP analogues were estimated to be 1.38 and $1.33 \mathrm{eV}$.

In addition, the ionization potentials (IP) of thin films of the polymers were characterized by photoelectron spectroscopy in air (PESA), and the LUMO levels were estimated from the difference of IP and the optical band gap. This method only affords an approximation of the LUMO energy, since it does not account for the exciton binding energy. However it is useful in this context to afford comparisons between polymers. As can be seen from Table 1, pDTTG-BT $(-5.14 \mathrm{eV})$ and pDTTG-DPP $(-5.20 \mathrm{eV})$ possess higher lying HOMO levels in comparison with pDTTG-TPD $(-5.33 \mathrm{eV})$, which we predict to contribute to an unfavourable decline of open circuit voltages $\left(V_{\mathrm{oc}}\right)$ in $\mathrm{BHJ}$ devices. The LUMO of pDTTG-BT is similar with pDTTG-TPD whereas the former has lower band gap, which usually enhances the photocurrent in the solar cells. Although we observed only small differences to the optical band gaps upon the inclusion of the longer alkyl chains, significant effects were observed in the energy levels of pDTTGL-BT, pDTTGL-TPD and pDTTGL-DPP, resulting in a lowering of both the HOMO and LUMO. For the BT and TPD co-polymers the energy levels shift away from the vacuum level by approximately $0.2 \mathrm{eV}$, whereas the effect is larger for the DPP polymer which may be due to the change of side-chain simultaneously on both the donor and acceptor co-monomers. The lower HOMO levels are rationalized by the inhibition of molecular coplanarity and polymer aggregation due to the stronger steric hindrance of the longer side-chains. Although the lower lying HOMO may be helpful to increase the $V_{\mathrm{oc}}$ of the resultant device, the LUMO levels appear too low, in particular for pDTTGL-DPP $(-4.32 \mathrm{eV})$, to lead to efficient charge transfer from the polymer to PCBM (LUMO ca. $-4.0 \mathrm{eV}$ ), eventually leading to inferior device performance.

\section{Photovoltaic properties}

To investigate the effects on photovoltaic performance of DTTG copolymers with various comonomers and alkyl side-chains, bulk heterojunction devices with a conventional device configuration of ITO/PEDOT:PSS/Polymers: $\mathrm{PC}_{71} \mathrm{BM} / \mathrm{Ca} / \mathrm{Al}$ were fabricated based on these five polymers. Similar coating conditions were employed in the process of fabrication in order to compare with the previously reported polymer pDTTG-TPD, and all five new polymers were coated under similar conditions. Hence $1: 2$ $(\mathrm{w} / \mathrm{w})$ ratio of polymer:PCBM blend solutions in dichlorobenzene at $80{ }^{\circ} \mathrm{C}$ were spun cast, resulting in films of $c a .100 \mathrm{~nm}$ thickness. As shown in Fig. 3 and Table 2, pDTTG-BT exhibits a slightly higher $J_{\mathrm{sc}}$ of $14.04 \mathrm{~mA} \mathrm{~cm} \mathrm{~cm}^{-2}$ compared to pDTTG-TPD $\left(13.85 \mathrm{~mA} \mathrm{~cm}^{-2}\right)$, most likely as a result of the reduced band gap, although the higher lying HOMO level leads to a reduction in $V_{\text {oc }}$ of $0.1 \mathrm{~V}$ compared to pDTTG-TPD $(0.81 \mathrm{~V})$. Therefore although the introduction of BT moiety successfully enhances the current density of the device, only a moderate PCE of $4.66 \%$ was achieved, limited by an unsatisfactory fill factor (FF) of $47 \%$, which we attribute to an imbalance of energy levels, solubility and crystallinity.

Despite the promising performance reported for some DPP containing polymers, pDTTG-DPP displayed a $J_{\mathrm{sc}}$ of $3.56 \mathrm{~mA}$ $\mathrm{cm}^{-2}$ accompanied by a $V_{\text {oc }}$ of $0.69 \mathrm{~V}$ and a $\mathrm{FF}$ of $35 \%$, leading to a disappointing PCE of $0.87 \%$. We assume the poor performance is attributable to the rather low LUMO level of pDTTGDPP, which is close to that of PCBM, perhaps leading to 


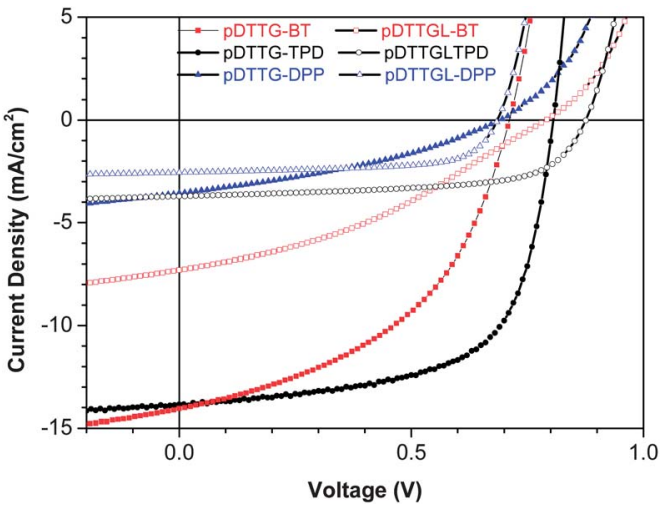

Fig. 3 EQE corrected Current-Voltage curves of $1: 2$ polymer/PC ${ }_{71} B M$ blend devices.

Table 2 Solar cell device characteristics

\begin{tabular}{lclll}
\hline Polymer & $J_{\text {sc }}\left(\mathrm{mA} \mathrm{cm}^{-2}\right)$ & $V_{\text {oc }}(\mathrm{V})$ & FF $(\%)$ & PCE $(\%)$ \\
\hline pDTTG-TPD $^{a}$ & 13.85 & 0.81 & 64 & 7.16 \\
pDTTG-BT & 14.04 & 0.71 & 47 & 4.66 \\
pDTTG-DPP & 3.56 & 0.69 & 35 & 0.87 \\
pDTTGL-BT & 7.30 & 0.79 & 35 & 2.04 \\
pDTTGL-DPP & 2.56 & 0.69 & 66 & 1.16 \\
pDTTGL-TPD & 3.71 & 0.88 & 63 & 2.06 \\
${ }^{a}$ Data from ref. 23. & & & &
\end{tabular}

insufficient driving force to promote charge generation and separation. ${ }^{3}$ This point was confirmed by PDTTGL-DPP, whose LUMO is even lower than the short chain analogue, and which exhibited a worse $J_{\mathrm{sc}}$ of $2.56 \mathrm{~mA} \mathrm{~cm} \mathrm{~cm}^{-2}$. A similar decline in photocurrent is also observed going from pDTTGL-BT to pDTTGL-TPD, in agreement with the LUMO level reduction. Although in both these cases the lower lying HOMO levels contribute to an improvement in open circuit voltages, this is not sufficient to offset the reduction in photocurrent, leading to an overall reduction in PCEs relative to pDTTG-BT and pDTTGTPD respectively. We note that for both pDTTGL co-polymers the increase of repeat unit mass upon introduction of the longer branched side-chains results in an effective reduction of the light absorbing conjugated backbone component in both cases, since the blend weight ratio remained constant for all materials. However this reduction of approximately $30 \%$ in the relative content of the conjugated polymer for both PDTTGL-BT and pDTTGL-TPD relative to pDTTG-BT and pDTTG-TPD is insufficient to account solely for the larger reductions in photocurrent observed (approximately 50\% and 75\% respectively), leading us to conclude that the reduction in relative LUMO level is also important. We note that the trend of $J_{\text {sc }}$ decline is in excellent agreement with the order of LUMO levels for these five polymers.

It appears that the different alkyl side-chains have a minor influence on the TPD and BT polymers in terms of fill factor, with fill factors of $64 \% / 63 \%$ and $47 \% / 35 \%$ for the 2-ethylhexyl/ 2-octyldodecyl chain polymers respectively. The inferior fill factors of the BT polymers can be reasonably explained by the reduced solubility of the BT polymers, leading to non-optimum intermixing of the polymer and PCBM during processing. Further studies on this material examining solvent mixtures and additives in an effort to enhance efficiency are in progress. On the other hand, a paradoxical situation is found for DPP polymers, where pDTTG-DPP shows a low fill factor of 35\% whilst the replacement of 2-ethylhexyl with the 2-octyldodecyl alkyl chain and the replacement of a linear chain on the DPP with a branched side-chain significantly promotes the $\mathrm{FF}$ of the resultant polymer to $66 \%$. As demonstrated above, both of these two polymers exhibit acceptable solubility in common organic solvents, so the differences in fill factor probably relate to the influence of the various alkyl side-chains on film microstructure.

\section{Microstructure}

To further understand the effect of microstructure of polymer films on device performance, wide-angle X-ray scattering (WAXS) and atomic force microscopy (AFM) measurements were performed. Thin films of polymers were fabricated identically to the OPV devices except that the evaporation of metal cathodes was not performed. The surface morphology from tapping mode AFM is shown in Fig. 4 (topography and phase images). Both pDTTG-BT and pDTTG-DPP display uniform and smooth films, with no evidence of detrimental large scale phase segregation. The replacement of the short side-chain with 2-octyldodecyl for the BT polymers increases the RMS roughness from $0.812 \mathrm{~nm}$ to $1.012 \mathrm{~nm}$, most likely due to the increased polymer crystallinity (see XRD discussion), but the surface morphology appears similar to the shorter chain polymer. However the domains of PDTTGL-TPD and PDTTGL-DPP significantly increase in size, such that we had to enlarge the scan area in order to obtain the features of morphology as shown in Fig. 4d and e. Qualitatively, the larger domain size, although unlikely to comprise pure polymer and/or fullerene regions, nevertheless suggests a non-optimal microstructure of the blend. This may be related to the high alkyl chain density for both of these polymers, since unlike the BT copolymer, both the TPD and DPP have additional solubilising side-chains. Due to the miscibility of fullerenes and conjugated polymers, ${ }^{40}$ larger domains are likely to contain isolated regions of fullerene within the polymer (or polymer within the fullerene) which can lead to rapid recombination of photogenerated carriers, and therefore the reduced photocurrents observed.

Fig. 5 shows the WAXS patterns of drop cast films from chlorobenzene solution on glass substrate, before and after annealing at $140{ }^{\circ} \mathrm{C}$. As shown in Fig. 5, pDTTG-BT and pDTTGTPD show clear diffraction peaks at $24.1^{\circ}$ and $24.7^{\circ}(2 \theta)$ corresponding to $d$-spacings of 3.69 and 3.60 A respectively, while the former displays a lamellar packing distance of $16.3 \AA$ from the peak at $5.4^{\circ}$ in comparison with $19.2 \AA$ from the peak at $4.6^{\circ}$ for the latter. The reduction in lamellar spacing for pDTTG-BT versus PDTTG-TPD is consistent with the reduced solubility and alkyl chain content of the BT polymer, but pDTTG-TPD still possesses a closer $\pi-\pi$ stacking, probably resulting from the 

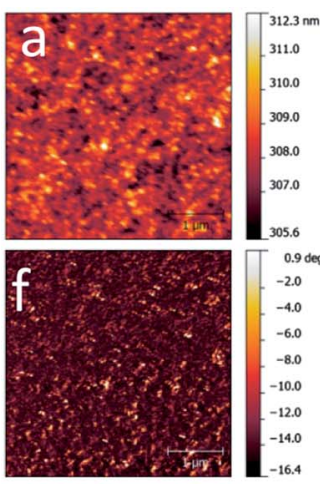

PDTTG-BT
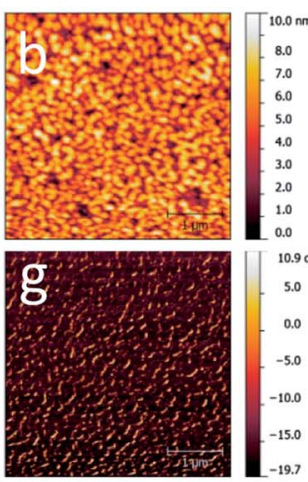

pDTTG-DPP

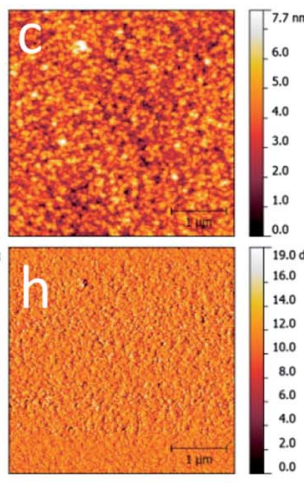

PDTTGL-BT

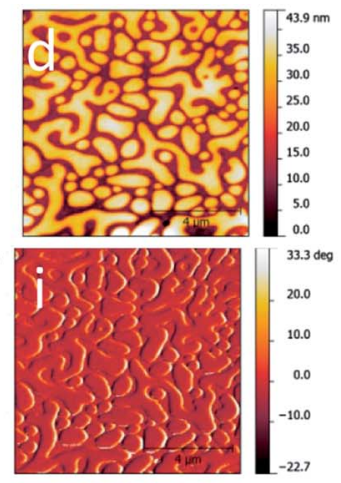

PDTTGL-TPD

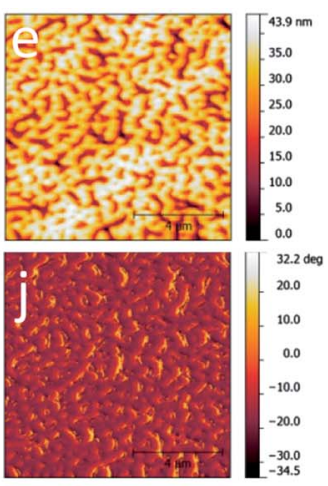

PDTTGL-DPP

Fig. 4 AFM topography (top) and phase (bottom) images of $1: 2$ polymer/PC ${ }_{71} B M$ blend films (area size $4 \times 4 \mu \mathrm{m}$ for a-c, f-h, and $10 \times 10 \mu \mathrm{m}$ for $\mathrm{d}$, e, i and j).

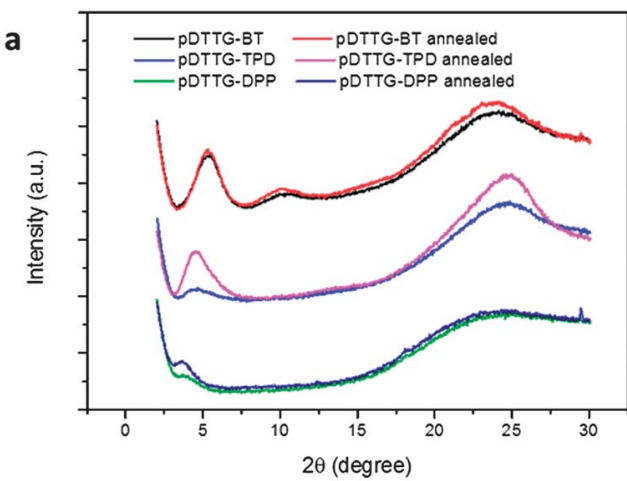

b

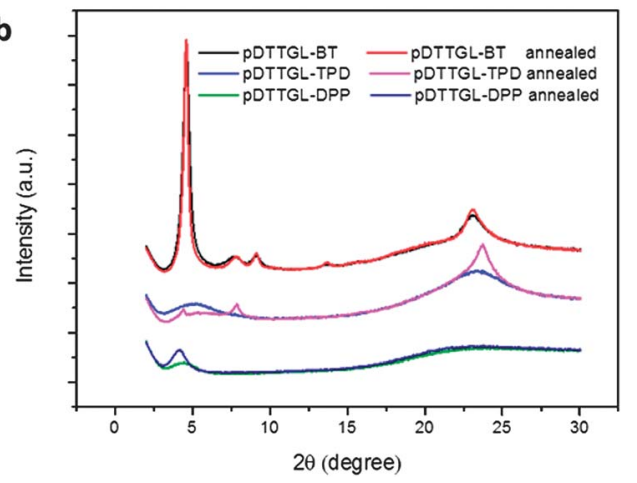

Fig. 5 X-ray diffraction pattern of films of polymers drop cast from chlorobenzene solution and thermally annealed at $140{ }^{\circ} \mathrm{C}$ for $10 \mathrm{~min}$. Traces offset for clarity. (a) for polymer containing 2-ethylhexyl bridges, (b) for polymer containing 2-octyldecyl bridges.

non-covalent interaction between the carbonyl groups and the hydrogen atoms of another molecule. The intensities of the $\pi-\pi$ and lamellar stacking peaks of pDTTG-TPD increase after annealing at $140{ }^{\circ} \mathrm{C}$ for 10 minutes, indicating an increase in polymer ordering, whilst no obvious change was found in the found in the pattern of pDTTG-BT, similar to pDTG-BT. ${ }^{26}$ In comparison with pDTTG-BT, pDTTGL-BT exhibits a slightly larger lamellar spacing (19.1 $\mathrm{\AA})$, as well as a narrower full-width half maximum (FWHM) for this lamellar peak $\left(0.52^{\circ}\right.$ versus $1.78^{\circ}$ for $\left.\mathbf{p D T T G - B T}\right)$, in addition to higher order peaks, suggesting a higher degree of crystallinity for the polymer with longer 2-octyldodecyl chains. This may be related to the higher molecular weight. The larger lamellar spacing of pDTTGL-BT relative to the short side-chain derivative may additionally increases the barrier for charge transport across domains. Both pDTTG-DPP and pDTTGLDPP show broad and weak peaks around $4^{\circ}$ and possibly $25^{\circ}$, and the annealing process appears to hardly influence the diffraction except for a slight increase in intensity of the lamellar peak. These results suggest that the presence of large amounts of bulky alkyl chains suppress the crystallisation of both DPP polymers in the solid state, which may hinder the charge carrier transport of the blend film of polymer and $\mathrm{PC}_{71} \mathrm{BM}$.

\section{Conclusions}

In conclusion, we synthesized five new polymers pDTTG-BT, pDTTG-DPP, pDTTGL-BT, pDTTGL-DPP and pDTTGL-TPD based upon the promising donor unit DTTG, in which BT, TPD and DPP were employed as acceptor comonomers to tune the molecular conformations and donor-acceptor interactions. Inclusion of BT or DPP units leads to a decrease in the band gap of polymers compared to the TPD polymer, enabling a better match with the solar spectrum and potentially enhancing photocurrent in OPV blend devices. However whilst an enhancement of the $J_{\text {sc }}$ for the pDTTG-BT device compared to pDTTG-TPD was observed, in the case of pDTTGDPP a sharp drop was observed, suggesting that tuning must be controlled within reasonable scopes. Furthermore, our studies illustrate that the nature and density of the alkyl sidechains have a significant impact on the polymer aggregation and film microstructure, with larger and more bulky sidechains leading to improved solubility and higher molecular weight. The combination of these integrated effects ultimately determined the performance of $\mathrm{BHJ}$ devices based on donoracceptor polymers.

\section{Acknowledgements}

The work was carried out in part under work supported by EPSRC Grant nos EP/G060738/1 and EP/I002936/1. 


\section{Notes and references}

1 C. Wang, H. Dong, W. Hu, Y. Liu and D. Zhu, Chem. Rev., 2011, 112, 2208.

2 Y. Li, Acc. Chem. Res., 2012, 45, 723.

3 H. Zhou, L. Yang and W. You, Macromolecules, 2012, 45, 607. 4 A. J. Heeger, Chem. Soc. Rev., 2010, 39, 2354.

5 J. M. Szarko, J. Guo, B. S. Rolczynski and L. X. Chen, J. Mater. Chem., 2011, 21, 7849.

6 G. Yu, J. Gao, J. C. Hummelen, F. Wudl and A. J. Heeger, Science, 1995, 270, 1789.

7 X. Yong and J. Zhang, J. Mater. Chem., 2011, 21, 11159.

8 R. L. Uy, S. C. Price and W. You, Macromol. Rapid Commun., 2012, 33, 1162.

9 J. D. Yuen and F. Wudl, Energy Environ. Sci., 2013, 6, 392.

10 Z. B. Henson, K. Mullen and G. C. Bazan, Nat. Chem., 2012, 4, 699.

11 B. C. Schroeder, R. S. Ashraf, S. Thomas, A. J. P. White, L. Biniek, C. B. Nielsen, W. Zhang, Z. Huang, P. S. Tuladhar, S. E. Watkins, T. D. Anthopoulos, J. R. Durrant and I. McCulloch, Chem. Commun., 2012, 48, 7699.

12 W. Li, K. H. Hendriks, W. S. C. Roelofs, Y. Kim, M. M. Wienk and R. A. J. Janssen, Adv. Mater., 2013, 25, 3182.

13 A. N. Sokolov, S. Atahan-Evrenk, R. Mondal, H. B. Akkerman, R. S. Sánchez-Carrera, S. Granados-Focil, J. Schrier, S. C. B. Mannsfeld, A. P. Zoombelt, Z. Bao and A. AspuruGuzik, Nat. Commun., 2011, 2, 437.

14 Y.-X. Xu, C.-C. Chueh, H.-L. Yip, F.-Z. Ding, Y.-X. Li, C.-Z. Li, X. Li, W.-C. Chen and A. K. Y. Jen, Adv. Mater., 2012, 24, 6356.

15 X. Wang, P. Jiang, Y. Chen, H. Luo, Z. Zhang, H. Wang, X. Li, G. Yu and Y. Li, Macromolecules, 2013, 46, 4805.

16 I. McCulloch, M. Heeney, M. L. Chabinyc, D. M. Delongchamp, R. J. Kline, M. Colle, W. Duffy, D. Fischer, D. Gundlach, B. Hamadani, R. Hamilton, L. Richter, A. Salleo, M. Shkunov, D. Sparrowe, S. Tierney and W. Zhang, Adv. Mater., 2009, 21, 1091.

17 Y.-J. Cheng, C.-H. Chen, T.-Y. Lin and C.-S. Hsu, Chem.-Asian J., 2012, 7, 818.

18 Y. Wu, Z. Li, X. Guo, H. Fan, L. Huo and J. Hou, J. Mater. Chem., 2012, 22, 21362.

19 H.-J. Yun, Y.-J. Lee, S.-J. Yoo, D. S. Chung, Y.-H. Kim and S.-K. Kwon, Chem.-Eur. J., 2013, 19, 13242.

20 H.-H. Chang, C.-E. Tsai, Y.-Y. Lai, D.-Y. Chiou, S.-L. Hsu, C.-S. Hsu and Y.-J. Cheng, Macromolecules, 2012, 45, 9282.

21 I. Meager, R. S. Ashraf, S. Mollinger, B. C. Schroeder, H. Bronstein, D. Beatrup, M. S. Vezie, T. Kirchartz, A. Salleo, J. Nelson and I. McCulloch, J. Am. Chem. Soc., 2013, 135, 11537.

22 Y. Wu, Z. Li, W. Ma, Y. Huang, L. Huo, X. Guo, M. Zhang, H. Ade and J. Hou, Adv. Mater., 2013, 25, 3449.

23 H. Zhong, Z. Li, F. Deledalle, E. C. Fregoso, M. Shahid, Z. Fei, C. B. Nielsen, N. Yaacobi-Gross, S. Rossbauer, T. D. Anthopoulos, J. R. Durrant and M. Heeney, J. Am. Chem. Soc., 2013, 135, 2040.

24 T. Lei, J.-Y. Wang and J. Pei, Chem. Mater., 2013, DOI: 10.1021/cm4018776.
25 C. Cabanetos, A. El Labban, J. A. Bartelt, J. D. Douglas, W. R. Mateker, J. M. J. Fréchet, M. D. McGehee and P. M. Beaujuge, J. Am. Chem. Soc., 2013, 135, 4656.

26 Z. Fei, M. Shahid, N. Yaacobi-Gross, S. Rossbauer, H. Zhong, S. E. Watkins, T. D. Anthopoulos and M. Heeney, Chem. Commun., 2012, 48, 11130.

27 J. W. Rumer, C. K. L. Hor, I. Meager, C. P. Yau, Z. Huang, C. B. Nielsen, S. E. Watkins, H. Bronstein and I. McCulloch, J. Org. Semicond., 2013, 1, 30.

28 H. N. Tsao, D. M. Cho, I. Park, M. R. Hansen, A. Mavrinskiy, D. Y. Yoon, R. Graf, W. Pisula, H. W. Spiess and K. Müllen, J. Am. Chem. Soc., 2011, 133, 2605.

29 Z. Fei, J. S. Kim, J. Smith, E. B. Domingo, T. D. Anthopoulos, N. Stingelin, S. E. Watkins, J.-S. Kim and M. Heeney, J. Mater. Chem., 2011, 21, 16257.

30 Y. Li, P. Sonar, L. Murphy and W. Hong, Energy Environ. Sci., 2013, 6, 1684.

31 K. H. Hendriks, G. H. L. Heintges, V. S. Gevaerts, M. M. Wienk and R. A. J. Janssen, Angew. Chem., Int. Ed., 2013, 52, 8341.

32 D. Gendron, P.-O. Morin, P. Berrouard, N. Allard, B. R. Ä̈ch, C. N. Garon, Y. Tao and M. Leclerc, Macromolecules, 2011, 44, 7188.

33 S. Tierney, M. Heeney and I. McCulloch, Synth. Met., 2005, 148, 195.

34 J. K. Park, J. Jo, J. H. Seo, J. S. Moon, Y. D. Park, K. Lee, A. J. Heeger and G. C. Bazan, Adv. Mater., 2011, 23, 2430.

35 M. J. Frisch, G. W. Trucks, H. B. Schlegel, G. E. Scuseria, M. A. Robb, J. R. Cheeseman, G. Scalmani, V. Barone, B. Mennucci, G. A. Petersson, H. Nakatsuji, M. Caricato, X. Li, H. P. Hratchian, A. F. Izmaylov, J. Bloino, G. Zheng, J. L. Sonnenberg, M. Hada, M. Ehara, K. Toyota, R. Fukuda, J. Hasegawa, M. Ishida, T. Nakajima, Y. Honda, O. Kitao, H. Nakai, T. Vreven, J. A. Montgomery, Jr, J. E. Peralta, F. Ogliaro, M. Bearpark, J. J. Heyd, E. Brothers, K. N. Kudin, V. N. Staroverov, R. Kobayashi, J. Normand, K. Raghavachari, A. Rendell, J. C. Burant, S. S. Iyengar, J. Tomasi, M. Cossi, N. Rega, J. M. Millam, M. Klene, J. E. Knox, J. B. Cross, V. Bakken, C. Adamo, J. Jaramillo, R. Gomperts, R. E. Stratmann, O. Yazyev, A. J. Austin, R. Cammi, C. Pomelli, J. W. Ochterski, R. L. Martin, K. Morokuma, V. G. Zakrzewski, G. A. Voth, P. Salvador, J. J. Dannenberg, S. Dapprich, A. D. Daniels, Ö. Farkas, J. B. Foresman, J. V. Ortiz, J. Cioslowski and D. J. Fox, Gaussian 09, Gaussian, Inc., Wallingford CT, 2009. 36 A. D. Becke, J. Chem. Phys., 1993, 98, 5648.

37 G. L. Gibson, T. M. McCormick and D. S. Seferos, J. Phys. Chem. C, 2013, 117, 16606.

38 G. C. Welch, R. C. Bakus, S. J. Teat and G. C. Bazan, J. Am. Chem. Soc., 2013, 135, 2298.

39 S. Qu, B. Wang, F. Guo, J. Li, W. Wu, C. Kong, Y. Long and J. Hua, Dyes Pigm., 2012, 92, 1384.

40 N. D. Treat, A. Varotto, C. J. Takacs, N. Batara, M. Al-Hashimi, M. J. Heeney, A. J. Heeger, F. Wudl, C. J. Hawker and M. L. Chabinyc, J. Am. Chem. Soc., 2012, 134, 15869. 